\title{
Acquisition Rates in University Libraries
}

\begin{abstract}
While the allocation of book funds in university libraries and the size of the ultimate collection have received considerable attention in the literature, suggestions for determining the annual acquisition rate have related primarily to numbers of students or the size of the collection, neither of which is satisfactory. A model for determining acquisition rates for currently published material for universities with extensive doctoral programs is developed. A basic rate is established for the library of a university with a specifically defined program. The rate is then modulated, based on variations in programs from the university as defined.
\end{abstract}

D

URING THE PAST FIFTY YEARS, the library literature has been replete with articles on the allocation of book funds in university libraries, but very little has been written on annual funding for book acquisitions or how to calculate and justify the acquisition rate necessary to provide adequately for academic and research requirements. The lack of discussion on determination of annual funding requirements is curious, for, as Rogers and Weber point out, "Of all policy issues confronting a university library, none is more central to the nature of the institution or has greater single impact on costs than the program for collecting books and other informational materials." 1 The size of collections and their exponential growth have been given attention both in textbooks and in the periodical literature but have been approached more often in terms of holding them in check rather than

Melvin J. Voigt is university librarian, University of California, San Diego. in meeting academic research requirements.

The preponderance of literature on university libraries today relates to the quite necessary objectives of cooperation and networking to improve access, while slowing down accelerating costs. There is danger that enthusiasm in this direction may result in a weakening of individual research libraries to a degree that advanced graduate programs and research are no longer possible. Dix, in a paper presented to the National Commission on the Financing of Postsecondary Education on behalf of the Association of Research Libraries, after an admirable discussion of the importance of research libraries, devotes the suggested action part of his paper almost entirely to methods of achieving economies and does not discuss the need for continued growth to maintain quality collections at every major university. ${ }^{2}$ It is most important that attention be paid to quantifying the accession rates essential to maintaining collections that will support advanced graduate education 
and research. This paper describes a model developed for this purpose.

\section{Size and Growth of Collections}

Many writers have made generalized statements on the importance of continuing development of the university library's collections. As Downs states, "A book collection that has stopped growing is a dead collection and soon loses most of its interest and value for the scholar." ${ }^{3}$ Major emphasis, however, has been on how large a collection is needed, giving the impression to many a naive university administrator that once the goal of $\mathrm{x}$ million volumes is reached, acquisitions can stop.

The most often quoted attempt to quantify college and university collection requirements, the Clapp-Jordan formula,${ }^{4}$ deals exclusively with collection size and does not consider acquisition rates. In the study of Ohio institutions from which the article was developed, ${ }^{5}$ Clapp and Jordan did consider the "amount of annual book fund" and recommended an acquisition rate of 6 percent, thus following the lead of other writers in an expectation of continuing exponential growth.

The 6 percent was calculated from Rider's finding that research libraries doubled in size approximately every sixteen years. Clapp and Jordan quote Rider's statement that "this may be asserted as almost axiomatic: unless a college or university is willing to be stagnant, unless it is willing not to maintain its place in the steady flow of educational development, it has to double its library in size every sixteen years, or thereabouts." ${ }^{\text {In }}$ correspondence Verner Clapp stated that the annual book fund discussion "was omitted from the published article as likely to add unnecessarily to sufficient trouble." 7 In an earlier letter Clapp stated that "when published in $C d R L$ (with numerous errors), the formula claimed nothing beyond an attempt to demonstrate a meth- od. . . . $8 \mathrm{He}$ considered the numbers used as experimental, expected that they should vary when applied to different educational institutions or groups of institutions, and was unhappy that they were generally accepted as gospel without further testing. The most thorough analysis of the Clapp-Jordan formula is that of McInnis, ${ }^{9}$ who found it difficult to determine rational collection size through empirical analysis, indicating that collection size is not the major consideration.

It has always seemed to this writer that in the university situation, when a reasonable start has been made in building an adequate research collection, first consideration must be given to maintaining a satisfactory acquisition ratea continuous flow of currently published material-and that ultimate size must become a secondary concern. Over an extensive time period, size has always been a meaningless term, for as long as scholarship continues and results in printed material or other physical substitutes for print, such material will be added to research libraries. The amount of these current acquisitions to be permanently housed and retained on campus will depend on an institution's ability to add library space, availability or ability to construct easily accessible storage, and on ease of access to other research collections in the geographical area for inspection of large quantities of material. When the acquisition rate is restricted to materials needed in situ, the possibilities of using interlibrary loan have been taken into account in determining that rate. Interlibrary loan availability, for practical purposes, then becomes a minor factor in determining permanent retention of those materials. Extensive use of interlibrary loan by a scholar is limited to materials that can be identified as relevant without inspection.

As noted above, most writers have expressed requirements for acquisition 
rates in terms of a percentage of the existing collection. Various studies, including those of Rider ${ }^{10}$ and the Purdue study, ${ }^{11}$ have concluded that the sixteen-year, or faster, doubling rate, established through examination of library growth statistics over considerable periods of time, would and should continue indefinitely. The result has been a belief that libraries should have everincreasing acquisition rates, the theory of "exponential growth." Various percentages have been adopted in longrange growth plans of university libraries and multicampus systems-the percentages usually varying from 4 to 6. It has become obvious that this approach is no longer viable. Factors, such as increased costs, decreased funding, better bibliographic access and networking, and the fact that the quantity of scholarly publishing is no longer accelerating, have resulted in few major libraries showing exponential growth patterns in the last few years.

\section{Calculation of Growth Rates}

If major emphasis is to be given to maintaining consistent acquisition rates, how can they be calculated and justified? Comparison with similar institutions has always been used and will continue to be of some value as a measure of adequacy. But there is a multiple mirror effect that could result in inadequacies everywhere, if comparisons alone are used as justification.

Almost all other formulas that have been used or proposed relate acquisition rates to numbers of students, a totally unsatisfactory solution. W. M. Randall, in 1931, pointed out: "It appears obvious, for example, that the number of students enrolled in courses in economics in College A can have no possible effect upon the number of authoritative and necessary books published during a year in the subject. . . . it is easy to see that the size of the student enrollment is not a factor in the budget of these purchases." 12 Massman and Patterson also make this point in their article on acquisition budgets: "Naturally the college with a larger number of students needs more duplicate copies, and it may also have a greater variety of programs. However, course for course and major for major there is no difference in the number of separate titles needed by any institution. . . ten students majoring in a subject area will need access to the same quantity of sources as one hundred students." 13 This is even more true for advanced graduate programs and scholarly research generally.

It would seem that a model or series of models should be developed that would permit a university or group of universities to establish minimum annual acquisition rates. The model should provide for continuing acquisitions that would change in quantity over a period of years only as variables in the model changed. The purpose of this article is to suggest and describe such a model. The calculation and the numbers used here would need to be tested in a variety of institutions before being generally adopted. Individual institutions would probably need to provide variations in some of the factors to meet specialized situations. However, the philosophy of the model is that a basic acquisition rate can be created that is relatively easy to understand and apply, and that every university will have additional factors that could be taken into account in developing the acquisition rate, but that the base rate should be high enough to allow for these additional factors, which will tend to average out and, therefore, need not complicate the model. The model, as described, has been applied to a number of universities and appears to yield results within the range of adequacy.

\section{DeVelopment OF THE MODEL}

Before the model can be developed, a fundamental division of the acquisi- 
tion program must be made. Acquisition of currently published books and journals must be separated from acquisition of retrospective materials. It is the acquisition of currently published books and journals that must be maintained at a relatively constant rate. While no library can reduce retrospective purchases to zero, there is flexibility in how rapidly retrospective collections are brought to any determined level of adequacy. Acquisition of current material is not as directly related to a library's existing collection as retrospective purchases are. A number of writers have recognized the importance of making this distinction. Meyer and Demos state that, among other things, an acquisition policy for current materials must recognize that "the pattern of spending between current and retrospective material will tend to shift as less and less of the budget need be allocated to filling lacunae. ... funds for current imprints will remain major (and probably increase, as the price of books and the quantity of books continue to rise) while funds set aside for retrospective buying will be less." 14

The model, as developed here, relates to that portion of acquisitions devoted to currently published materials. It seems clear that any attempt to break down acquisitions of currently published materials to specific numbers of volumes for every undergraduate major, every master's program, and every doctoral program leads to a morass of meaningless numbers, due primarily to the great amount of overlap between fields, the extensive use of materials in several fields by students and scholars in other fields, and the variations in breadth and depth which programs with the same or comparable titles will have in various universities. Thus, while the model results in a specific number of justified volumes, ultimate use or distribution of acquisition funds is not de- termined by the model, because (1) all of the factors are interrelated and do not in themselves necessarily take into account all of the needs of a specific subject or field, and (2) the factors are set at levels necessary to include general and related fields not specifically covered in the model.

The model is intended for general universities with extensive advanced graduate (Ph.D.) programs in a definable and broad array of fields. The model then provides for modulation of a basic acquisition rate for the "university" as defined-the modulation based on additional professional programs, additions or subtractions of advanced graduate programs to or from those included in the definition, increasing numbers of undergraduate students, and, where applicable, extensive, sponsored research programs and ease of access to other major libraries.

\section{Basic Principles}

The basic principles of the model are as follows:

1. Rates for acquisition of current books and journals are related to the totality of academic needs, which remain relatively constant and which require continuing funding largely unrelated to levels of existing retrospective collections.

2. The level of current book and journal acquisition rates provided through use of the model supplies those materials without which quality master's and advanced graduate programs could not exist; but with dependence on other institutions, particularly those close enough to be easily used for material not in demand frequently enough to warrant duplication. Special requirements at every university result in unique materials not requiring duplication at other nearby institutions, materials that 
can and should be made generally available.

3. A university, for purposes of the model, is defined as offering advanced graduate (Ph.D.) work in American/English and at least two other major European literatures; in at least three social sciences; in the major sciences (chemistry, physics, biology, and mathematics); in history, with concentrations in a variety of geographic areas and time periods; in psychology; and in philosophy. A base acquisition rate for current books is then established for a university as defined (M.1).

4. The established rate of acquisitions of current materials (M.1) is expected to provide for minimal needs of undergraduate students in the fields beyond those included in the definition.

5. The rate for current materials is set at a level to provide the materials needed regularly by master'slevel graduate students, whether or not there are advanced graduate programs in all fields in which there are master's programs. Every university will have some master's programs with special library requirements. The basic current acquisition rate (M.1) is set at a level to provide for these programs without further additions.

6. The basic acquisition rate (M.1) for current materials for the university as defined is a composite, which, because of subject interrelationships and the breadth of coverage inherent in the definition of a university campus, cannot be determined by the numerical addition of specific subject book requirements in individual academic fields and at various levels, but must be based on cumulative experience.

7. If advanced graduate programs do not exist in the university as defined in 3 , some deductions in current acquisitions can be made, but the deductions should not eliminate materials needed in these fields for undergraduate and master's programs (M.2).

8. Current acquisition allocations for additional advanced graduate programs, professional schools, and for other specialized doctoral programs with a high degree of independence in their literatures are added to the basic rate at specified rates (M.3 and M.4).

9. Additions are made for additional advanced graduate programs in foreign literatures, social sciences, and certain physical sciences (earth sciences or geology and astronomy) (M.3). Fields, such as area programs or combined language-history programs, are considered as additions in either the language or social science area, but not in both, even when separate graduate degree programs are established. Thus, if doctoral programs exist in both Asian studies and Oriental languages, or in both Islamic studies and Near Eastern languages, an addition is made for an additional foreign literature or for an additional social science, but not for both. Area programs, such as African or Far Eastern, are considered as single additions in either foreign literature or social science. Foreign languages and literatures, other than those of the major literature-producing countries, are grouped and considered as single additions, e.g., Scandinavian language and literature or Slavic language and literature.

10. The base acquisition rate, plus additions as provided in M.3 and M.4, is set at levels that will pro- 
vide for additional advanced graduate programs without further increases. Such programs are either contained in broader areas specifically provided for, e.g., medicine, agriculture, engineering, biology, or have relatively small literatures of their own, with heavy dependence on the literature of fields covered in the base, or in ones added under M.3 and M.4. Examples of advanced graduate programs for which no additional volumes are added include agricultural economics, anatomy, archaeology, atmospheric science, biochemistry, biomedical engineering, biophysics, botany, classical archaeology, comparative literature, computer science, demography, ecology, endocrinology, engineering physics, entomology, genetics, geochemistry, information science, logic, meteorology, microbiology, neuroscience, pathology, pharmacology, physiology, plant physiology, public policy, romance languages or philology, soil science, speech, statistics, wildlife resources, and zoology.

11. Where large undergraduate enrollments exist, provision is made for additional material, primarily duplicate copies (M.5). No additions are made for numbers of graduate students, in that duplicate copies are usually not required for graduate work and because the number and breadth of fields covered, rather than the number of students, are the governing factors.

12. In universities with large amounts of sponsored research, and where the informational requirements of such research are supplied by the university library, additional books and journals (largely duplicates) are required (M.6).
13. To make an allowance for isolation of universities not within easy access to other universities, an addition factor based on distance is included (M.6). While interlibrary loans can be made regardless of distance, efficient research, especially in advanced graduate work, depends on examination of large quantities of material. Thus, the absence in the area of other major libraries that can be easily consulted means that an isolated university library must regularly obtain more material than would otherwise be necessary. The value of additional libraries that can easily be used by scholars and advanced students cannot be overemphasized. Even when neighboring universities include the same subject fields in their academic programs, much additional material will be available for consultation. As stated by Arms, "For a homogenous group of libraries the number of new titles obtained by adding the holdings of another library is proportional to the number of books added and the size of the library is immaterial." 15

\section{Quantitative Factors}

The suggested quantitative factors to be used in the model are as follows:

M.1 Acquisition rate No. of Volumes of currently published materials for a university as defined .......... 40,000 (For purposes of this model, currently published materials are defined as books or journals published in the year received or in the previous year. Thus, in 1975 , currently published materials bear either 1974 or 1975 publication dates.)

M.2 Subtraction rate per field for fewer than 
two European literatures, or three social sciences, or if psychology or philosophy are not included . 1,000

M.3 Addition rate per field for additional advanced graduate programs in foreign literatures, social sciences, earth sciences (geology), and astronomy, subject to the limitations noted in 9 and 10 above ............ 2,000

M.4 Addition rates for advanced graduate professional schools or subjects:

Agriculture ........ 5,000

Architecture ........ 1,000

Art $\ldots \ldots \ldots \ldots \ldots \ldots . \quad 3,000$

Business Administration. 2,000

City and Regional Plan-

ning $\ldots \ldots \ldots \ldots \ldots \ldots \quad 2,000$

Drama ............ 2,000

Education .......... 3,000

Engineering $\ldots \ldots \ldots \ldots \quad 1,000$

per major area

4,000

maximum

Law ............ 8,000

Library Science ....... 1,000

Medicine .......... 8,000

Medicine-Related

Professions $\ldots \ldots \ldots \ldots . \quad 1,000$

per major area

4,000

maximum

Music $\ldots \ldots \ldots \ldots \ldots \quad 3,000$

Oceanography $\ldots \ldots \ldots . \quad 3,000$

Religious Studies ..... 2,000

Social Welfare ....... 1,000

Veterinary Science .... 2,000

(It is assumed that related pure science materials exist in the 40,000 base, thus reducing the requirements in medicine, veterinary science, engineering, oceanography, and agriculture to the levels indicated; that social science materials help support business administration, city and re- gional planning, education, and law; that the base allocation helps support architecture, music, art, drama, and library science; that philosophy helps support religious studies; and that requirements for all other areas are included within the totals for the campus.)

M.5 Addition for undergraduate students.

For each 2,000 undergraduate students or fraction thereof over 5,000 undergraduate students . . . . 1,000

M.6 Addition for sponsored research. For each $\$ 15$ million in sponsored research contracts or grants

M.7 Addition for lack of access to other research libraries:

Travel time, less than one hour each way, to a research library of 2 million or more volumes

Travel time, one to two hours each way, to a major research library ... 10,000 Travel time, more than two hours each way, to a major research library . 20,000 Table 1 illustrates the use of the formula for the University of California, San Diego (UCSD), and a number of hypothetical institutions.

\section{USE OF THE MODEL}

As stated earlier, this type of model is not useful if one attempts to include retrospective acquisitions. Retrospective books and journals, and microforms, which are largely retrospective, must be added at rates related to the level of the existing collection, the funding available, and the staff available to do retrospective selection. The appropriate level might be from 5,000 to 25,000 vol- 
TABLE 1

USE OF MODEL TO DETERMINE ACQUISITION RATES FOR CURRENTLY PUBLISHED MATERIALS

\begin{tabular}{|c|c|c|c|c|c|}
\hline & & UCSD & Institution $\mathrm{A}$ & Institution B & Institution C \\
\hline M.1 & Base & 40,000 & 40,000 & 40,000 & 40,000 \\
\hline \multirow{4}{*}{ M.3 } & $\begin{array}{l}\text { Subtractions } \\
\text { Additions: }\end{array}$ & - & - & $-4,000^{a}$ & - \\
\hline & Foreign literatures & $2,000^{\mathrm{b}}$ & $14,000^{\circ}$ & - & $8,000^{\mathrm{d}}$ \\
\hline & Social sciences & $2,000^{\circ}$ & $14,000^{t}$ & - & $6,000^{\mathrm{z}}$ \\
\hline & Earth science, astronomy & $4,000^{\mathrm{h}}$ & $4,000^{\mathrm{h}}$ & $2,000^{1}$ & $2,000^{1}$ \\
\hline \multirow[t]{17}{*}{ M4. } & Advanced graduate and professional & & & & \\
\hline & Agriculture & - & $\overline{-1}$ & 5,000 & 一 \\
\hline & Architecture & - & 1,000 & - & - \\
\hline & Art. & - & 3,000 & - & 3,000 \\
\hline & Business administration & - & 2,000 & - & - \\
\hline & City and regional planning & - & 2,000 & - & 2,000 \\
\hline & Drama & - & 2,000 & - & - \\
\hline & Education & - & 3,000 & 3,000 & - \\
\hline & Engineering & $3,000^{k}$ & $4,000^{1}$ & 一 & - \\
\hline & Law & - & 8,000 & 一 & $\overline{1} 000$ \\
\hline & Library science & $\overline{0}-1$ & 1,000 & - & 1,000 \\
\hline & Medicine & 8,000 & 8,000 & - & 8,000 \\
\hline & Medicine-related professions & - & $4,000^{\mathrm{m}}$ & - & $2,000^{\mathrm{n}}$ \\
\hline & Oceanography & 3,000 & - & - & 3,000 \\
\hline & Religious studies & - & - & - & 2,000 \\
\hline & Social welfare & - & 1,000 & - & - \\
\hline & Veterinary science & - & - & - & 2,000 \\
\hline M.5 & Undergraduate suppl. & 1,000 & 7,000 & - & 3,000 \\
\hline M. 6 & Sponsored research & 4,000 & 4,000 & - & 1,000 \\
\hline M.7 & Access factor & 20,000 & - & 10,000 & 20,000 \\
\hline & TOTAL & 87,000 & 112,000 & 56,000 & 103,000 \\
\hline
\end{tabular}

a No Ph.D. in philosophy, psychology, and only one in foreign literatures and two in social sciences.

b Ph.D.s in French, German, Spanish.

c Ph.D.s in French, German, Spanish, Classics, Italian, Scandinavian, Oriental, Slavic, Near Eastern.

d Ph.D.s in French, German, Hispanic, Russian, Chinese, Italian.

- Ph.D.s in anthropology, economics, linguistics, sociology.

1 Ph.D.s in anthropology, archaeology, criminology, economics, geography, Latin American studies, linguistics, paleontology, political science, sociology (Ph.D.s also in Asian studies and Near Eastern studies, included under foreign literatures.)

g Ph.D.s in anthropology, geography, linguistics, sociology, Near Eastern studies, African studies.

h $\mathrm{Ph} . \mathrm{D} . \mathrm{s}$ in earth sciences and astronomy.

$1 \mathrm{Ph} . \mathrm{D}$, in geology.

$1 \mathrm{Ph} . \mathrm{D}$. in astronomy.

${ }^{k} \mathrm{Ph}$.D. in aerospace, applied physics, applied mechanics.

$1 \mathrm{Ph} . \mathrm{D}$. in chemical, civil, electrical, mechanical, industrial.

$\mathrm{m}$ Doctoral degrees in dentistry, pharmacy, public health, nursing.

${ }^{n}$ Doctoral degrees in optometry, pharmacy.

umes per year and can, of course, vary from year to year.

A factor of great importance in applying the model and in determining retrospective acquisition rates, but one that appears to be impossible to insert, is that of the quality of the scholarly work at a university. It is evident that an institution that puts little emphasis on research-that has few scholars who are productive, in terms both of quality and quantity of research-has far less need for extensive library resources than another university with an equal number of advanced graduate students, but staffed with some of the top scholars of the nation and with great emphasis on research of high quality. If a university has no aspiration for a research reputation, it can lower the base and add-on factors significantly; but if it has or expects to obtain and maintain 
a position of scholarly leadership, it will find that minimal acquisition rates along the lines of those suggested in the model will probably be necessary.

Gifts and exchanges have not been considered in the construction of the model. Most gifts are of retrospective materials and therefore should not affect the model. Exchanges, if they contribute materials which would otherwise be purchased within the construction of the model, should be deducted from the total when acquisition funding is calculated.

Finally, as has been made clear, the numbers used here in the model, or any others that might be substituted, are obviously based on judgment. Most librarians who have commented on the model believe them to be of the right order of magnitude. Work with the model indicates that the base rate of 40,000 volumes could not be reduced more than 5,000 or increased more than 10,000 without destroying its viability. Obviously, increases or decreases in the rate of scholarly publications might change the base. If there is concern about using experience, judgment, and comparison in establishing the base rate and other factors, it should be pointed out that many other factors in education, such as student-faculty ratios, space allocations, and administrative support ratios also depend on experience, judgment, and comparison with other institutions.

\section{REFerences}

1. Rutherford D. Rogers and David C. Weber, University Library Administration (New York: Wilson, 1971), p.113.

2. William Dix, "The Financing of the Research Library," College \& Research Libraries 35:252-58 (July 1974).

3. Robert B. Downs, "Development of Research Collections in University Libraries," in William H. Jesse, ed., The Library in the University (Hamden, Conn.: Shoe String, 1967), p.60-75.

4. Verner W. Clapp and Robert T. Jordan, "Quantitative Criteria for Adequacy of Academic Library Collections," College \& Research Libraries 26:371-80 (Sept. 1965). See also "Corrigenda," College \& Research Libraries 27:72 (Jan. 1966).

5. Verner W. Clapp and Robert T. Jordan, The Libraries of the State-Assisted Institutions of Higher Education in Ohio-Their Maintenance and Development-Guidelines for Policy (Washington, D.C.: Council on Library Resources, 1964).

6. Fremont Rider, The Scholar and the Future of the Research Library: A Problem and Its Solution (New York: Hadham Pr., 1944), p.9.

7. Personal letter written by Verner W. Clapp, president, Council on Library Resources, to Robert M. Hayes and the author on March 28, 1967.
8. Personal letter written by Verner W. Clapp to the author on February 16, 1967.

9. R. Marvin McInnis, "The Formula Approach to Library Size: An Empirical Study of Its Efficacy in Evaluating Research Libraries," College \& Research Libraries 33:190-98 (May 1972).

10. Rider, The Scholar and the Future of the Research Library.

11. Oliver C. Dunn, Warren F. Seibert, and Janice A. Scheuneman, The Past and Likely Future of 58 Research Libraries, 19511980: A Statistical Study of Growth and Change (Lafayette, Ind.: University Libraries and Audio Visual Center, Purdue University, 1965).

12. William M. Randall, "The College-Library Book Budget," Library Quarterly 1:42135 (1931).

13. Virgil Massman and Kelly Patterson, "A Minimum Budget for Acquisitions," College \& Research Libraries 31:83-88 (March 1970).

14. Betty J. Meyer and John T. Demos, "Acquisitions Policy for University Libraries: Selection or Collection,"' Library Resources \& Technical Services 14:395-99 (Summer 1970).

15. W. Y. Arms, "Duplication in Union Catalogues," Journal of Documentation 29:37379 (Dec. 1973). 